\title{
URODYNAMIC STUDIES IN THE SURGICAL TREATMENT OF BENIGN PROSTATIC HYPERPLASIA
}

\author{
MARCELO L. DE LIMA, N. RODRIGUES NETTO JR. \\ Division of Urology, University of Campinas Medical Center, Unicamp, Campinas, São Paulo, Brazil
}

\begin{abstract}
Objective: We compared the clinical and urodynamic outcome of men with lower urinary tract symptoms with and without previous urodynamic evaluation submitted to transurethral resection of the prostate.

Materials and Methods: A prospective and randomized study was performed in 315 patients who underwent transurethral resection of the prostate. In 151 patients (group A) with a mean age of 63 years, transurethral resection of the prostate was performed without a prior urodynamic study, and group B, 164 patients with a mean age of 61 years, underwent a urodynamic study prior to surgical procedure. In group B, only obstructed patients were selected for surgery. All patients had I-PSS higher than 15 and underwent at least 2 uroflowmetry and flow was lower than $10 \mathrm{ml} / \mathrm{sec}$. At 6-month follow up, patients in both groups underwent the I-PSS questionnaire and pressure / flow study.

Results: The symptomatology and uroflowmetry did not display different behavior between the groups. The mean postoperative score for group A was $8.87+3.27$ and for group B was $9.32+3.14(\mathrm{p}=$ $0.22)$. The mean postoperative uroflow for group A was $17.0+2.1 \mathrm{~mL} / \mathrm{s}$ and for group $B$ was $16.6+$ $2.2 \mathrm{~mL} / \mathrm{s}(\mathrm{p}=0.15)$.

Postoperative, in group A, 27 patients (17.8\%) were obstructed and in group B, 16 patients $(9.75 \%)$ were obstructed $(\mathrm{p}=0.03)$.

Conclusion: The study suggests that the previous urodynamic study is not the only factor related to the success of surgical outcome; and therefore, the symptomatology and uroflowmetry associated would be enough during the preoperative routine studies for BPH patients.
\end{abstract}

Key words: benign prostatic hyperplasia; urodynamics; symptoms; therapeutic; surgery

Int Braz J Urol. 2003; 29: 418-22

\section{INTRODUCTION}

Lower urinary tract symptoms (LUTS) have a high prevalence among adult men. Prostate growth does not necessarily mean the presence of lower urinary tract symptoms generated by prostatic obstruction of infravesical urinary flow.

We find great difficulty, in daily practice, to determine the precise diagnosis in order to select the adequate treatment. Studies have demonstrated that there is no correlation between prostate enlargement and obstruction, since small prostates may be obstructive and large prostates may not cause obstruction. The presence of an infravesical obstructive factor verified by an urodynamic study does not necessarily indicate the presence of symptoms, with the functional capacity of the detrusor also being important (1). Urodynamic studies are currently the best method for assessing the different etiologies of lower urinary tract symptoms.

In the present study, the relationship between symptoms and infravesical obstruction was analyzed in 315 patients who underwent transurethral resection of the prostate (TURP). 


\section{MATERIALS AND METHODS}

Between March 1993 and March 2001, 452 patients with lower urinary tract symptoms were evaluated in our service. All patients were analyzed by subjective and objective parameters.

The protocol included a complete medical and a thorough physical examination, as well as a complete urologic examination consisting of urinalysis, urine culture, creatinine, prostate specific antigen (PSA) and renal and transrectal ultrasound.

All patients underwent at least 2 uroflowmetry studies using the Urosystem/DS-5600® apparatus.

Symptomatology was evaluated by the International Prostate Symptom Score (I-PSS) which contains 7 questions, 4 questions related to voiding symptoms and 3 related to filling symptoms. Score of 0 to 7,8 to 19 and 20 to 35 represent mild, moderate, and severe symptoms, respectively (2). The questionnaire was translated and validated into Portuguese (3) and patients received guidance about how to fill it out. The study was approved by the hospital institutional ethics committee review board.

Patients were excluded from the study if they had been exposed to drugs, such as alpha agonists, anticholinergic, cholinergic, and diuretic agents, estrogens, androgens, antihypertensive medications, or other agents within the previous 2 weeks. Other exclusion criteria consisted of a history or evidence of prostate cancer, pelvic irradiation, urethral stricture, or surgery for $\mathrm{BPH}$ or evidence of active urinary tract stone disease, neurogenic bladder dysfunction, hydronephrosis, or urinary tract infection within the 3 months before the study.

A total of 113 patients were excluded of the study in this phase. Thus, 339 patients from 58 to 81 years old (mean age 67) were selected for the study. All patients had I-PSS higher than 15 and flow lower than $10 \mathrm{~mL} / \mathrm{sec}$.

Patients were prospectively randomized in two groups. Group A consisted of 151 patients who underwent TURP without a prior urodynamic study and group B consisted of 188 patients who underwent an urodynamic study prior to the surgical procedure.

The urodynamic evaluation was performed using the Urosystem/DS-5600â apparatus, connected to a $6 \mathrm{~F}$ rectal catheter for recording the abdominal pressure and a $6 \mathrm{~F}$ urethral catheter for recording the vesical pressure, with the patient standing. The catheters were connected to pressure transducers located at the level of the patient's pubic symphysis. For the filling of the bladder, $0.9 \%$ saline infusion was introduced via an $8 \mathrm{~F}$ urethral catheter, with an infusion rate of $50 \mathrm{ml} /$ minute.

The vesical and abdominal pressures were recorded and also the detrusor pressure (defined as the vesical pressure minus the abdominal pressure) and uroflow rate. This examination included cystometry and pressure - flow study (PFS) and in all patients the measures were obtained in duplicate.

The bladder outlet obstruction (BOO) factor was defined in according to the criteria established by the International Continence Society (ICS) (4). Utilizing the maximum flow values (Qmax) and the detrusor pressure at maximum flow (PdetQmax), it was seen that: a) when PdetQmax - 2 Qmax > 40, the pressure / flow study indicates obstruction; b) when PdetQmax - 2 Qmax $<20$, the pressure / flow study indicates absence of obstruction; c) in intermediate situations, the test result is equivocal obstruction.

In group A the mean I-PSS was $21.78 \pm 3.40$ and the mean flow was $6.8 \pm 1.4 \mathrm{~mL} / \mathrm{s}$.

In group B, 24 (12.8\%) patients were not obstructed or had equivocal obstruction and were excluded from the study. The equivocal obstruction according to the ICS criteria is similar to the equivocal zone on the Abram-Griffiths nomogram, which also relates the detrusor pressure to the urinary flow. These patients underwent TURP and are part of an ongoing study. In group B a total of 164 patients were obstructed. The mean I-PSS was $21.99 \pm 3.05$ and the mean flow was $6.9 \pm 1.3 \mathrm{~mL} / \mathrm{s}$.

Therefore, the study is based on a total of 315 patients. Group A had 151 patients (median age 63 years) and group B had 164 patients (median age 61 years).

Prostate volume was $28.72 \mathrm{~g} \pm 7.88$ in group A and $27.63 \mathrm{~g} \pm 1.64$ in group B.

The transurethral resection of the prostate was performed by the technique of lateral gutters according with Greene's principles (5). The operations were randomly performed by 3 members of the staff. 
All the procedures were performed using the same type of resectoscope (Karl Storz ${ }^{\circledR} 26 \mathrm{~F}$ ), the same electric source and the same irrigation fluid.

At a 6-month follow up, patients in both groups A and B underwent the I-PSS questionnaire and pressure / flow study to determine the number of obstructed patients after TURP. This is the only time that the I-PSS questionnaire and uroflowmetry were redone and this is the frame at which results were calculated for all patients.

The ANOVA variance analysis statistical test was used to determine whether there was an advantage in the surgical outcome based on a prior urodynamic study.

\section{RESULTS}

The following parameters were analyzed for both groups: a) pre and postoperative I-PSS variation; b) pre and postoperative uroflowmetry results; c) postoperative urodynamic results.

Symptomatology (I-PSS): The mean preoperative score for group A was $21.78 \pm 3.40$ and for group B was $21.99 \pm 3.05$. There was no statistically significant difference between the groups $(\mathrm{p}=0.56)$. The mean postoperative score for group A was $8.87 \pm 3.27$ and for group B was 9.32 \pm 3.14. There was no statistically significant difference between the groups $(p=0.22)$. The percentage of decrease in I-PSS for group A was $59.43 \%$ and for group B was $57.64 \%$. There was no statistically significant difference between the groups $(p=0.22)$.

Uroflowmetry: The mean preoperative uroflow for group A was $6.8 \pm 1.4 \mathrm{~mL} / \mathrm{s}$ and for group B was $6.9 \pm 1.3 \mathrm{~mL} / \mathrm{s}$. There was no statistically significant difference between the groups $(p=0.70)$. The mean postoperative uroflow for group $A$ was 17.0 $\pm 2.1 \mathrm{~mL} / \mathrm{s}$ and for group B was $16.6 \pm 2.2 \mathrm{~mL} / \mathrm{s}$. There was no statistically significant difference between the groups $(p=0.15)$. The percentage of increase in uroflow for group A was $148.52 \%$ and for group B was $140.43 \%$. There was no statistically significant difference between the groups $(\mathrm{p}=0.13)$.

Obstruction: The objective was to determine the number of patients who were obstructed after TURP. The presence of postoperative urinary obstruction was evaluated by the urodynamic study. In group A, 27 patients (17.8\%) and in group B, 16 patients $(9.75 \%)$ were obstructed. In group $A$, the presence of obstruction was statistically greater than in group $\mathrm{B}(\mathrm{p}=0.03)$.

\section{DISCUSSION}

Lower urinary tract symptoms (LUTS) increase with age and moderate to severe LUTS occur in approximately $25 \%$ of men over 50 years old $(2,6)$ Thus many patients look for a urologist due to their urinary symptoms and the inconvenience they cause. Consequently, the objective of any treatment is to relieve the symptoms and evaluate the role they perform in the efficacy of the treatment.

The pathophysiology of LUTS is multifactorial (7-9). Bladder outlet obstruction (BOO) is one of the main causes of LUTS; but detrusor factors such as detrusor instability and impaired contractility can contribute to the development of LUTS. Nevertheless, in view of the lack of correlation between symptoms, prostate enlargement and BOO, the effect of the symptoms in the lower urinary tract remain controversial $(2,10,11)$. There is a strong tendency in the world literature not to associate symptoms with the presence of obstruction (11).

At present, the most utilized method to confirm infravesical obstruction is the pressure / flow study (12-16). Urodynamics distinguish low flow secondary to hypoactivity of the detrusor from the low flow caused by obstruction.

In addition to this, some authors acknowledge that urodynamic analysis can be used to predict the symptomatic outcome after TURP. Unobstructed men have lower success rate for symptomatic outcome than those with obstruction (78\% vs. 93\%) $(17,18)$. However, the severity of LUTS does not correlate well with urodynamic obstruction, and up to a third of men with LUTS are not obstructed (19).

Those who are against performing pressure / flow studies question the reproducibility and standardization of the techniques utilized in urodynamic studies. The best standardization has been reached by following the parameters furnished by the International Continence Society. There is evidence 
that even individual variation in performing urodynamic studies rarely leads to alterations with respect to the type of obstruction diagnosed (20).

Nonetheless, urodynamic assessments are not totally innocuous, with significant evidence of discomfort and urinary infections associated with performing the examination, as well as imposing additional cost to the patient or to the institution. For many urologists, the use of urodynamics is also limited by the difficulty of access to the examination, requiring adequate training for accomplishing it and a high cost for the acquisition of appropriate equipment. The quality of many of the examinations performed in daily practice is also questioned. Therefore, few urologists recommend the routine use of pressure / flow studies for patients with urinary tract symptoms and suspected $\mathrm{BOO}$ caused by BPH, and with possible indication for TURP (21). The best indicator of successful treatment remains relief of symptoms (22).

In an AUA survey only $11 \%$ of the American urologists reported the use of urodynamics in routine evaluation of men with LUTS. There is the concept that only patients presenting to referral centers have urodynamic studies and not those at the community based. However, a study at the community based as well as at the referral centers showed that the urodynamic characteristics of the patients assessed for lower urinary tract symptoms were similar. Therefore, the referred patients do not represent a highly select population. (23).

Uroflowmetry and post-void residual urine measurements are well accepted among urologists. These are simple and non invasive examinations, although the literature reports that uroflowmetry has a high incidence of error (24). Uroflowmetry is accepted in the selection of cases for urodynamic among symptomatic patients, $88 \%$ of those with Qmax $<10 \mathrm{~mL} / \mathrm{s}$ have infravesical obstruction, compared with 54\% of the patients with Qmax between 10 and $15 \mathrm{~mL} / \mathrm{s}$ and $24 \%$ of those with Qmax $>15 \mathrm{~mL} / \mathrm{s}$. Therefore, urodynamic studies would be indicated for patients with Qmax over $10 \mathrm{~mL} / \mathrm{s}$, and with possible indication for surgery.

The symptomatology, measured by the I-PSS, showed similar behavior between the groups, without a statistically significant difference, clearly questioning the necessity of the pressure / flow studies prior to the surgical procedure. In group A, operation was performed on symptomatic patients with or without obstruction, a situation completely different from group $B$, in which only the obstructed patients were operated on.

Although TURP has been considered a procedure for relieving $\mathrm{BOO}$, many patients with non urodynamic obstruction benefit from surgery. The symptomatic outcome after TURP in men with LUTS was not different between groups 1 and 2 . Therefore, the best indicator of successful treatment remains relief of symptoms (22).

These results are in accordance with previous studies which have shown lack of association of symptom scores with urodynamic findings $(23,24)$. The study suggests that the previous urodynamic study is not the only factor related to the success of surgical outcome; and therefore, the symptomatology and uroflowmetry associated would be enough during the preoperative routine studies for BPH patients.

\section{REFERENCES}

1. Hald T: Urodynamics in benign prostatic hyperplasia: A survey. Prostate Suppl. 1989; 2: 69-74.

2. Garraway WM, Collins GN, Lee RJ: High prevalence of benign prostatic hyperplasia in the community. Lancet. 1991; 338: 469-71.

3. Netto NR Jr., Lima ML: The influence of patient education level on the International Prostatic Symptom Score. J Urol. 1995; 154: 97-9.

4. Abrams P: New words for old: lower urinary tract symptoms for "prostatism". BMJ. 1994; 308: 92930.

5. Greene LF: Transurethral Surgery. In: Walsh PC, Gittes RF, Perlmutter AD, Stamey TA (eds), Campbell's Urology. Philadelphia, WB Saunders. 1986; $5^{\text {th }}$ ed, pp. 2815-45.

6. Sagnier PP, MacFarlane G, Richard F, Botto H, Teillac P, Boyle P: Results of an epidemiological survey using a modified American Urological Association symptom index for benign prostatic hyperplasia in France. J Urol. 1994; 151: 1266-70.

7. Lepor $\mathrm{H}$ : The pathophysiology of lower urinary tract symptoms in ageing male population. Br J Urol. 1993; 81 (suppl. 1): 29-33.

8. Mardersbacher S, Pycha A, Schatzl G, Mian C, Klingler $\mathrm{CH}$, Marberger M: The aging lower urinary tract: a 
comparative urodynamic study of men and women. Urology. 1998; 51: 206-12.

9. Kakizaki H, Koyanagi T: Current view and status of lower urinary tract symptoms and neurogenic lower urinary tract dysfunction. BJU Int. 2000; 85 (Suppl. 2): 25-30.

10. Ko DSC, Fenster HN, Chambers K, Sullivan LD, Jens M, Goldenberg SL: The correlation of multichannel urodynamic pressure-flow studies and American Urological Association symptom index in the evaluation of benign prostatic hyperplasia. J Urol. 1995; 154: 396-8.

11. Abrams P: In support of pressure-flow studies for evaluating men with lower urinary tract symptoms. Urology. 1994; 44: 153-5.

12. Ezz El Din K, Kiemeney LALM, de Wildt MJAM, Debruyne FMJ, de la Rosette JJMCH: Correlation between uroflowmetry, prostate volume, postvoid residue, and lower urinary tract symptoms as measured by the International Prostate Symptom Score. Urology. 1996; 48: 393-7.

13. El Din K, Kiemeney LALM, de Wildt MJAM, Rosier PFWM, Debruyne FMJ, de la Rosette JJMCH: The correlation between bladder outlet obstruction Ezz and lower urinary tract symptoms as measured by the International Prostate Symptom Score. J Urol. 1996; 156: 1020-5.

14. Sirls LT, Kirkemo AK, Jay J: Lack of correlation of the American Urological Association Symptom 7 Index with urodynamic bladder outlet obstruction. Neurourol Urodyn. 1996; 15: 447-57.

15. Abrams P, Donovan JL, de la Rosette JJMCM, Schafer $\mathrm{W}$. and the ICS-"BPH" study group: International Continence Society "Benign Prostatic Hyperplasia" study: background, aims and methodology. Neurourol Urodyn. 1997; 16: 79-91.

16. McConnell JD, Barry MJ, Bruskewitz RC, Bueschen AJ, Denton SE, Holtgrewe HL, et al.: Benign prostatic hyperplasia: diagnosis and treatment. Clinical Practice Guidelines, number 8. AHCPR Publication N. 94-0582.
Rockville, Maryland: Agency for Healthcare Policy and Research, Public Health Service, U.S. Department of Health and Human Services. 1994; February.

17. Jensen KM-E, Jorgesen JB, Mogensen P: Urodynamics in prostatism II. Prognostic value of pressure-flow study combined with stop-flow test. Scand J Urol Nephrol Suppl. 1988; 114: 72-7.

18. Robertson AS, Griffiths C, Neal DE: Conventional urodynamics and ambulatory monitoring in the definition and management of bladder outflow obstruction. J Urol. 1996; 155: 506-11.

19. Gerber GS: The role of urodynamic study in the evaluation and management of men with lower urinary tract symptoms secondary to benign prostatic hyperplasia. Urology. 1996; 48: 668-75.

20. Nitti VW, Kim Y, Combs AJ: Voiding dysfunction following transurethral resection of the prostate: symptoms and urodymanic findings. J Urol. 1997; 157: 600-3.

21. Netto NR Jr., Lima ML, Netto MR, D’Ancona CAL: Evaluation of patients with bladder outlet obstruction and mild International Prostate Symptom Score followed up by watchful waiting. Urology. 1999; 53: 314-6.

22. Witjes WPJ, Wildt MJAM, Rosier PFWM, Caris CT, Debruyne FM, de la Rosette JJ: Variability of clinical pressure-flow studies variables after 6 months of watchful waiting in patients with lower urinary tract symptoms and benign prostate enlargement. J Urol. 1996; 156: 1026-34.

23. Fusco F, Groutz A, Blaivas JG, Chaikin DC, Weiss JP: Videourodynamic studies im men with lower urinary tract symptoms: a comparison of community based versus referral urological prectices. J Urol. 2001; 166: 910-3.

24. De la Rosette JJ, Witjes WPJ, Schafer W, Abrams P, Donovan JL, Peters TJ, et al.: Relationships between lower urinary tract symptoms and bladder outlet obstruction:results from ICS-"BPH" study. Neurourol Urodyn. 1998; 17: 99-102.

\section{Correspondence address:}

Received: May 5, 2003

Dr. Marcelo Lopes de Lima

Accepted: June 9, 2003

Rua Maestro João de Túlio, 55 / 72

Campinas, SP, 13024-160, Brazil

Fax: + 5519 3236-1177

E-mail:mar.lima@terra.com.br 